\title{
Make to Innovate: Blending of Project-based Learning and Flipped Class- room Pedagogies to Provide Real-world Engineering Experiences to Engi- neering Students
}

\section{Mr. Matthew Nelson, Iowa State University}

My background and interests are in RF and embedded systems as it relates to the aerospace engineering field. However, recently I have been doing research and have an interest in engineering education and how we can improve our education to our students. I have a B.S. in Electrical Engineering and a M.S. in Computer Engineering both from Iowa State University. I am now working towards my PhD in Engineering Education in the Human Computer Interaction (HCI) program at Iowa State University.

Currently, I am a faculty member of the Aerospace Engineering Department at Iowa State University as the direcotor for the Make to Innovate program at Iowa State University. This program provides our students with an opportunity to do hands-on projects and includes everything from underwater to space projects. In addition to my duties at Iowa State University, I also serve as the president of the Stratospheric Ballooning Association. This organization aims to promote, educate, and encourage collaboration for high-altitude balloon projects.

Dr. Benjamin Ahn, Iowa State University

Mrs. Christine Nicole Nelson, 


\title{
Make to Innovate: Blending of a project-based learning and flipped classroom pedagogies to provide real-world engineering experiences to engineering students
}

\begin{abstract}
The Make to Innovate program at Iowa State University in the Aerospace Engineering department has been operating for seven years. We implemented this program to give students across multiple disciplines and different levels of experience the ability to learn through experiential learning. The goal of the program is to reinforce students' understanding of engineering fundamentals, engage students with faculty and industry experts, and to augment the students' skills to include professional development skills such as teamwork, leadership, and communications. The program uses a Project Based Learning (PBL) framework to give students a hands-on approach to solving engineering problems. Students work on their own in their team environments to solve the problems needed to complete the project.

In this paper, we outline details on how we have implemented this program. We include discussion on the pedagogy used in creating and implementing of the program. We also discuss the assessment we use for measuring both the students' progress and success in the program. This includes discussion on the homework and other assignments that we assign to the students. We will show how we incorporate our industry partners by requiring students to meet with them and how they serve as technical advisors for the project. Finally, as this program has been operating for seven years, we will discuss the lessons that we have learned in implementing this program, the changes we have made over the years and some of the results we have gathered.
\end{abstract}

\section{Introduction}

Make to Innovate (M:2:I) is a program that began in Fall 2011. The concept behind this program is to give students hands-on experience through solving real-world problems. The course was designed to be a unique approach to teaching students variety of skills that include both engineering, project management, and professional skills. The classes involved in Make to Innovate uses a flipped classroom approach which does not have an assigned class time. Instead, each project arranges weekly team meetings and work times to complete the tasks at hand. We established a student leadership team for each project that allows the students to have some autonomy in how they operate. This student leadership aids in running meetings and serves as the contact point for the project. Finally, we developed a unique approach in how we assess success 


\section{ENROLLMENT AND PROJECTS FOR MAKE TO INNOVATE}

FALL 2011 - SPRING 2018

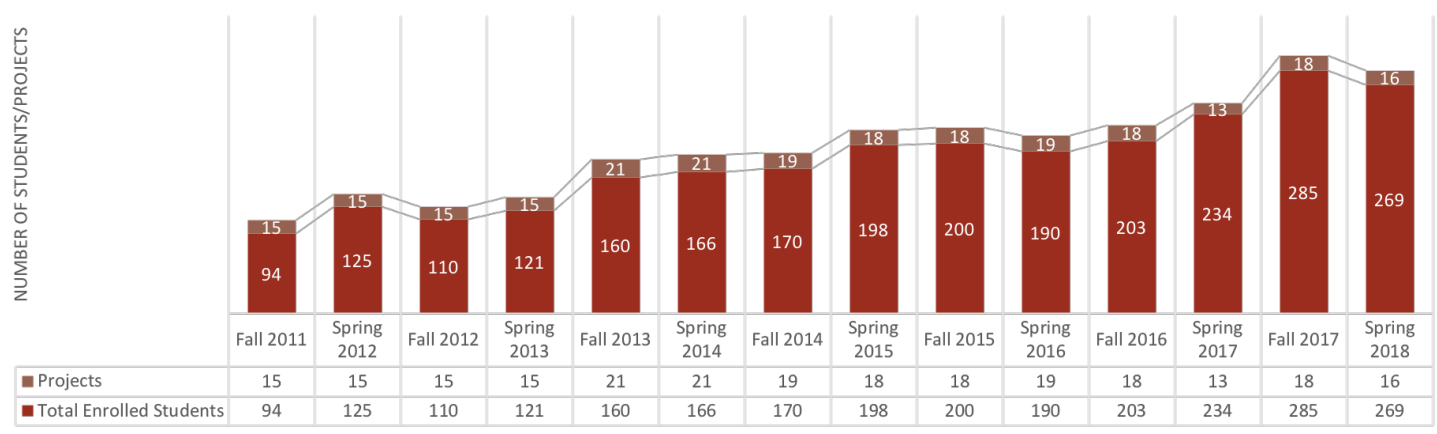

Figure 1: Student enrollment and the number of projects in the program.

and whether students were successful not only in accomplishing their goals but in learning new skills and improving their existing skills.

\section{Background information}

In 2011, the program started with approximately ninety students with fifteen different projects. These projects included our rocket projects, high altitude balloon project, and CubeSat project. As shown in Figure 1 and Figure 2, enrollment in the program has grown to over two hundred students. The number of projects has varied over time as the program matured to one that balanced between the number of students on a project and team. Teams are now capped at no more than 6 students per team with most projects averaging 3 teams per project.

The Make to Innovate program operates under two courses, a sophomore-level course (AerE 294), and a senior level course (AerE 494). The sophomore level course is restricted to freshman and sophomore students and is a one-credit course. We limit the senior-level course to juniors and seniors. We offer the senior-level course at two or three credits. Students that take on a leadership role must enroll at three credits, and all other students enroll at two credits.

Due to the popularity of the program and the growth shown in Figure 2, a decision was made to cap enrollment in both courses. This cap was implemented starting with the Fall 2018 semester. We capped AerE 294 at 80 students, and AerE 494 at 170 students. The total enrollment is now capped at 250 students. We implemented this change to keep enrollment numbers to a manageable level based on the resources available and to maintain the quality of the education for the students. The Fall 2018 semester saw a total student enrollment of 220 students.

Another method used to curb enrollment was adding a pre-requisite for the AerE 294 course. We determined that incoming Freshman to the program were also the highest group to drop out of the program during mid-term. This drop out would lead to many projects having reduced students to complete their tasks for the semester. This problem was compounded with a record enrollment of freshman during the Fall 2017 semester which can be seen in Figure 3.

Feedback from Junior and Senior students reported that taking time to train Freshman was a drain 


\section{M2I Current Enrollment Trends}

350

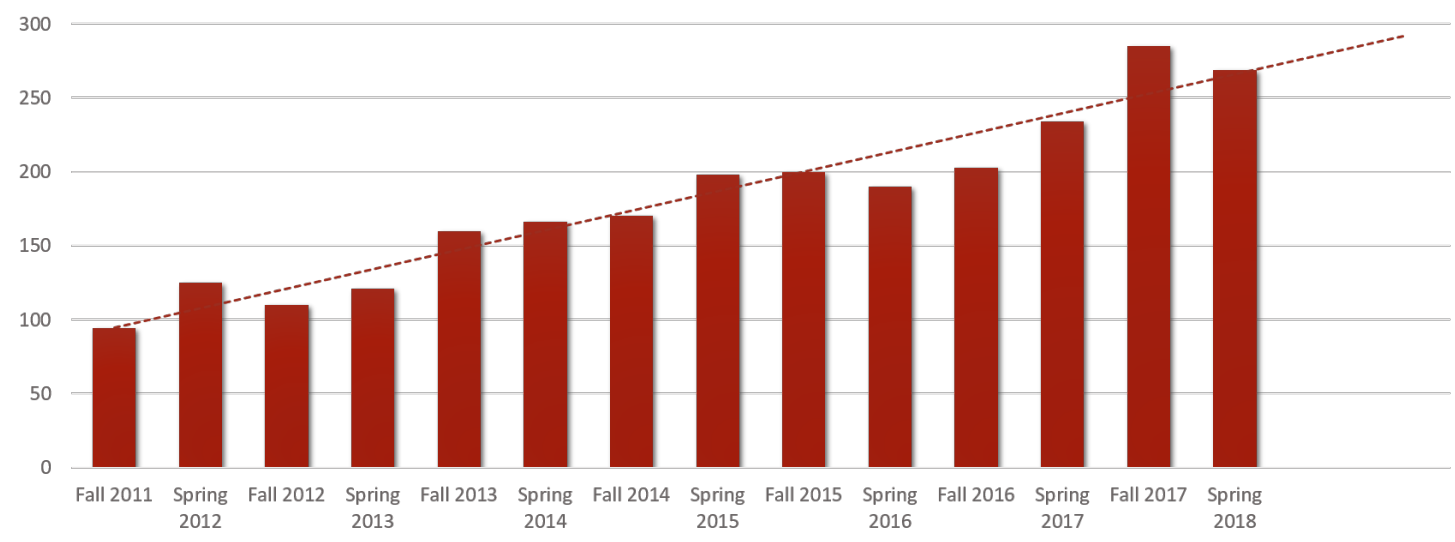

Figure 2: Enrollment in the program since the program was introduced.

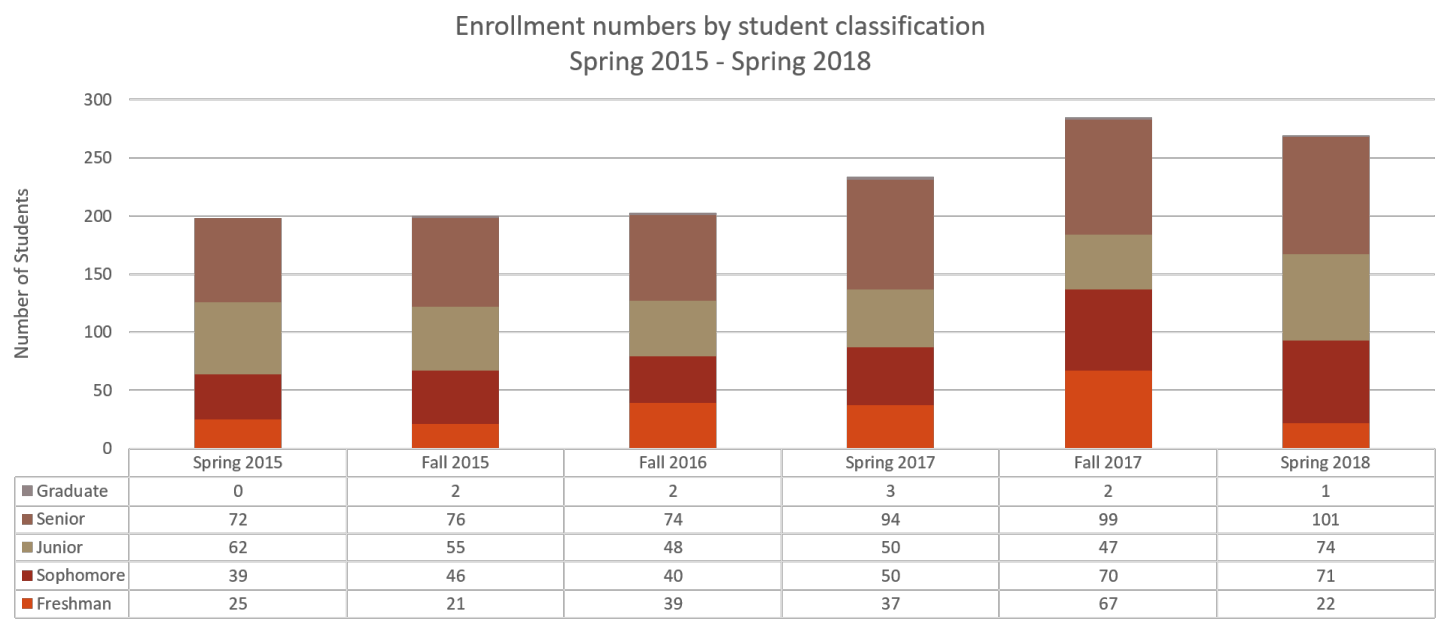

Figure 3: Breakdown of student enrollment based on their classification. 


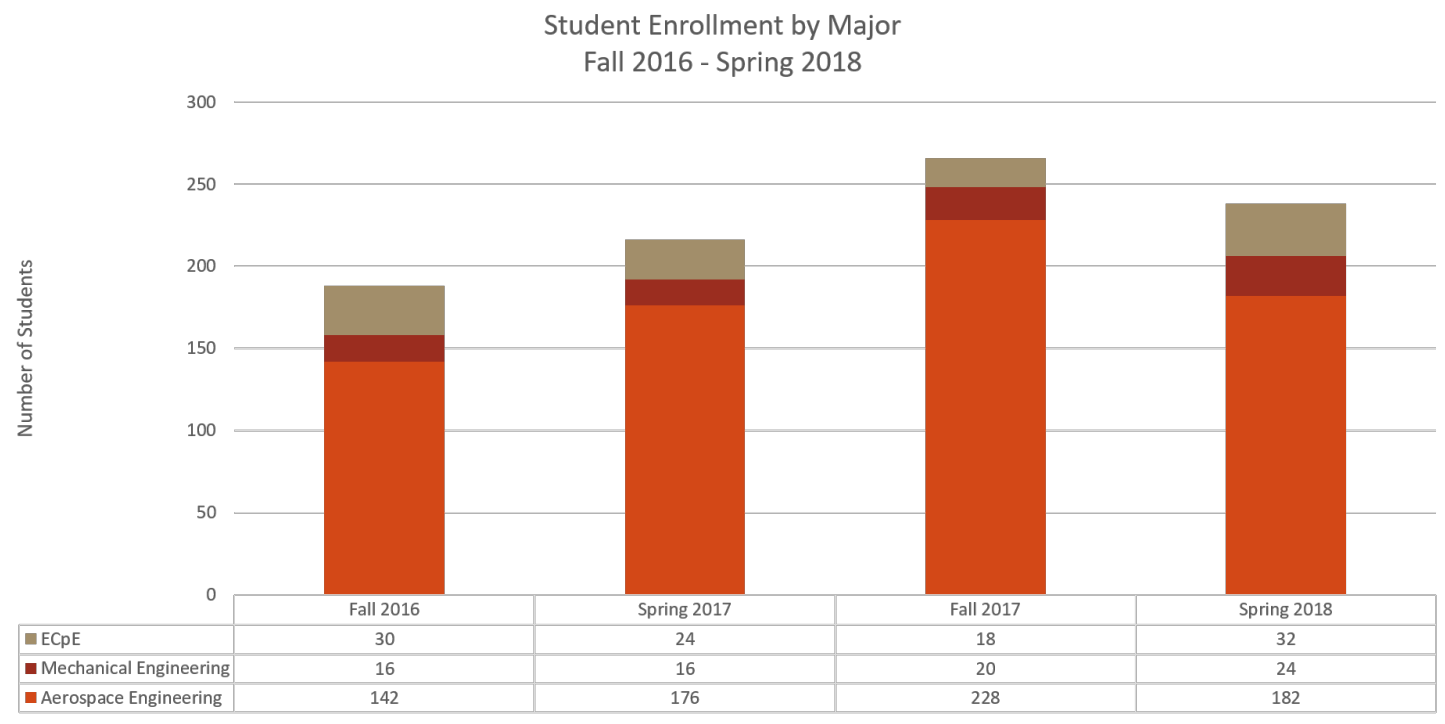

Figure 4: Enrollment with breakdown by major.

to their resources and resulting in tasks not being completed on time or at all. Based on this information, a pre-requisite of the Engr 101 course would stem the first-semester Freshman from being in the program. We choose the Engr 101 course as this is an introduction to engineering that all students are required to take. As such, it spans across multiple departments and gives students some of the fundamental engineering skills needed.

The makeup of the courses is predominantly Aerospace Engineering students. The composition for each semester can be seen in Figure 4. One reason that there is a majority of aerospace engineering students is due to the program being housed in and run by the Aerospace Engineering department. Another reason is that Aerospace engineering students are able to use up to six credits for their technical elective and other departments either do not accept it or at a lower number.

We are continuing to have more departments accept the program as a technical elective and to improve the diversity of the program. Continued development of the program also includes recruiting students from outside the College of Engineering and bringing students from science majors, business majors, and design. Many of the projects we have need to have a diverse set of skills to be successful, and we encourage students from all majors to be involved if possible.

\section{Resources}

To execute a program like Make to Innovate, we require several resources to ensure the success of the program. As this program is hands-on and involves engineering projects, a facility is required where students can meet, work, design, fabricate and test their work. This lab space was modeled after a makerspace and is housed in a 4,000 square foot repurposed lab space. This large of space allowed us to provide students with work benches, storage areas, computer lab, conference room, and tools needed. We equipped the lab with several 3D printers, a CNC machine, a mill, an 


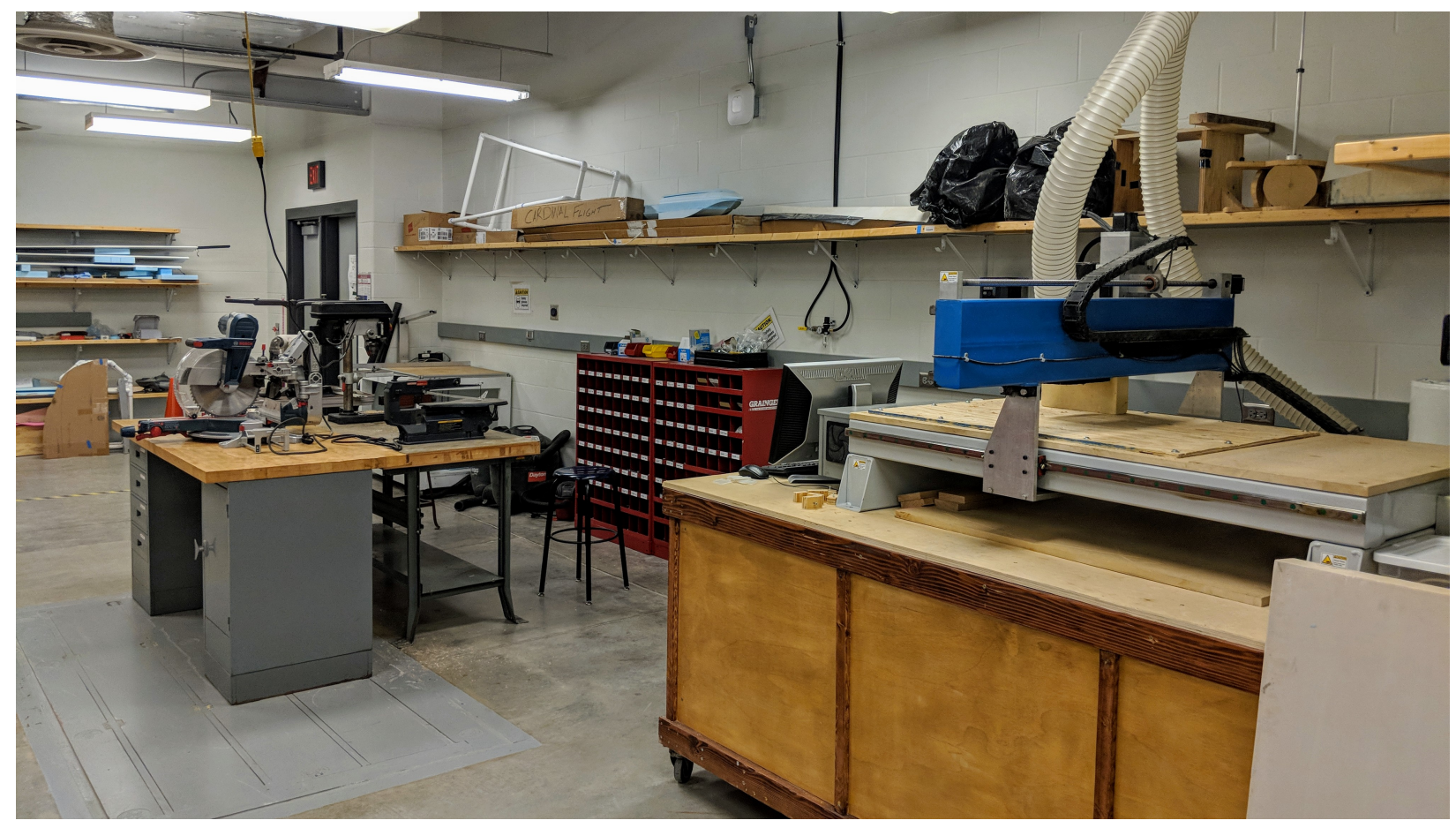

Figure 5: The lab space is equipped with a CNC, mill and additional tools for students to use for their projects.

electronics workbench, and a variety of powered and unpowered hand tools. A picture of some of the larger equipment we have, the CNC and mill can be seen in Figure 5.

The lab is monitored by student lab technicians that are trained in safety procedures, using the equipment and in using the check in and check out the system used to track hand tools. A picture of our tool crib where tools are housed can be seen in Figure 6 These student technicians are vital in keeping the lab open for extended hours that go until 8 p.m. Monday through Thursday, 6 p.m. on Friday and from 10 a.m. to 4 p.m. on Saturday. This process has worked very well, and the lab has had no major accidents and is often cited as the "cleanest" workspace on campus from visiting administrators.

Make to Innovate has a budget that is made up from both requests for the student projects and in the operation of the lab. The Make to Innovate lab has an operational budget of approximately $\$ 40,000$ that goes towards consumable supplies, replacement of tools, course costs, and student salaries. Approximately $\$ 70,000$ goes towards the student projects themselves which gives a total annual budget of approximately $\$ 110,000$. This total budget does not include the salaries for the Make to Innovate Director or Program Coordinator. These salaries are paid directly from the Aerospace Engineering department.

Each project team requests funding from Make to Innovate at the beginning of the semester by completing a project charter. This is a competitive process which is based on the need and funding available. After evaluation of each charter, the funds are distributed to each project. We determine if a project should receive funding based on the goals of the project and if they align well with our goals of the program. A project that has well defined goals and will expose students 


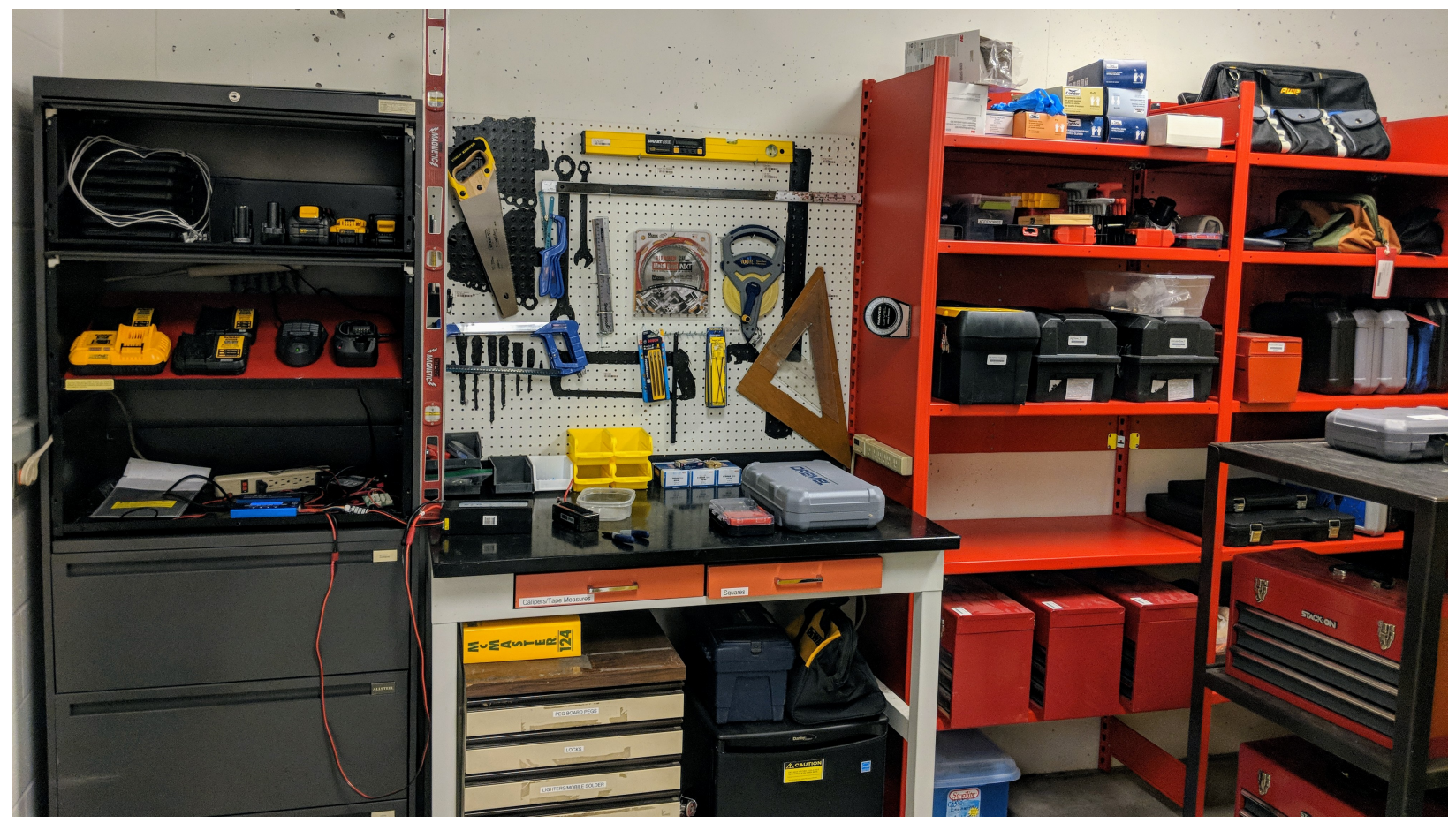

Figure 6: The lab space is equipped with a variety of hand tools, both powered and unpowered that can be checked out.

to a hands on learning process are often funded. Projects that also have support from a faculty member and again have well defined goals are also usually funded. If a project needs additional funding, we will work with the projects in obtaining funding from other sources such as additional donations, the Iowa Space Grant Consortium or other grants. Additional funding can also be gathered through Iowa State University's own version of a GoFundMe page.

Make to Innovate can sustain this budget due to the support of several key players. Boeing is the most significant contributor and donates funds every year to the Make to Innovate fund. Collins Aerospace (previously known as Rockwell Collins) is also a significant contributor to Make to Innovate. We obtain the rest of the funding through grants from the Iowa Space Grant Consortium, the Aerospace Engineering department, and additional donations received from other sources.

Make to Innovate has partnered with several companies not only to help support the program but, just as valuable, is to have access to industry experts that can work with the students. This invaluable service provides students with an advisor that can provide their industry experience to the project. This experience plays a significant role in teaching students how to carry something from design to reality and in learning new professional development skills. Students are able to build networking skills with potential co-workers and businesses which can lead to future employment. This has lead to many students securing internships, co-ops and even full time employment at these companies. We have alumni from our program that then come back and serve as technical advisors for our projects. We have around forty students that are alumni that keep in touch with us on a regular basis that have received positions thanks to their involvement in 
Make to Innovate.

\section{Teaching Philosophy}

When creating the Make to Innovate program, we developed a teaching philosophy that guides us on how we run the program. This philosophy we have is stated as follows: "To reinforce students' understanding of engineering fundamentals, engage students with faculty and industry experts, and to augment the students' skill set to include professional development skills through interactive, hands-on learning." It is through this philosophy that we have designed the Make to Innovate program in regards to how we interact, teach, and assess the students.

Make to Innovate is designed to complement, not compete, with other courses. Students need to take the knowledge and technical skills they acquire through the classes they take and apply them to tasks needed to make the project successful. While students may pick up some new skills through Make to Innovate, the principal idea is that we are reinforcing the knowledge they have.

Make to Innovate uses a hands-on approach in the learning process. We want our students to not only work on the design or to solve a problem presented, but also develop a solution that can be tested. All projects within Make to Innovate has goals that involve some level of design, build, and learning from the process. It is, for this reason, Make to Innovate has the slogan of "Design, Build, Learn".

We wish to engage students in more than just learning engineering skills. Engineering students today are often required to have additional skills outside of what they learn in the classroom [1]. The Accreditation Board for Engineering and Technology (ABET) also requires that students learn other skills then the math, science, and engineering we teach them [2]. Through this hands-on process students need to work in a team environment and need to work together to solve the problems they have with their project [3]. This process is done with guidance from the Make to Innovate administration team, faculty advisors and technical advisors.

\section{Learning Outcomes}

Both the sophomore and the senior level courses have learning outcomes associated with them. These learning outcomes focus on the hands-on skills, project management, and professional development skills they will develop and the professional development skills. These outcomes define our objectives for each class and what we expect the students to learn through the process. The following are the learning outcomes for the sophomore level course, AerE 294X.

By the end of the course, students are expected to learn the following outcomes:

- Will be able to use basic engineering principles to design, build and test a product,

- develop both written and oral communication skills,

- will be able to communicate and interact in a team environment effectively, 
- understand the basics of contributing to a team,

- understand the basics of how the Make to Innovate program operates.

The sophomore level course is taken as a one-credit course and with the expectation the students enrolled in this course are at the freshman or sophomore level. As such, we do not expect that these students will possess the required engineering skills to carry out all of the necessary tasks for their team. Instead, we see this as an opportunity for these students to begin acquiring these skills and to receive mentoring from their upperclassmen peers. It is for this reason that we purposefully mix both under and upper class-men in the teams.

The senior level course has similar but has additional outcomes added to it. We expect a higher level of involvement from the students at this level which is the reason we increase the credits from one to two. It is also at this level that students can serve in a leadership role, either as project leader or a team leader. For students serving in a leadership role, the credit requirement is three credits.

Student leadership is assigned by the instructors and is based on the students interest, abilities and any past leadership experience. This information is collected from a survey sent at the beginning of the semester that asks the students which project they wish to serve on and if they have interest in a leadership position and why. Through this survey we determine which students would be successful in leading their teams and projects. We also take feedback from the students themselves. If the students request a person to lead them and they meet all of our requirements, they are often promoted to that position.

By the end of the course, students are expected to learn the following outcomes:

- Will be able to define design requirements,

- develop a work plan and objectives to complete their project,

- will use engineering principles to design, build, test a product,

- will develop communication skills, written and oral, to effectively communicate the project team's process and results,

- will develop skills for working within a team environment,

- will develop skills in the leadership of a team.

Students that serve in a leadership role has altered expectations as well. In a leadership role, students will not be using their engineering skills as much as they will use more professional and project management skills. We tell students that in accepting a leadership role, they should expect a higher load in managing the team or project and a reduced load in solving engineering problems.

\section{Pedagogical Approach}

Make to Innovate uses Project Based Learning (PBL) as our framework and implements this with a flipped classroom. Projects serve as the foundation for the course and all students work towards 
the goals of the project. The project helps to bring purpose and motivation to the students as they work towards to the goals of the project. We then divide each project into teams, usually between two and four teams per project. These teams allow for team-based learning and organize specific tasks to that team. As shown in Figure 7, all projects have a project leader and under them are the team leaders. The faculty advisors, technical advisors and the Make to Innovate faculty and staff are there to support the students and aid them in learning new skills.

This hands-on approach is not a new concept and has been used at other institutions such as Rose-Hulman [4], Arizona State University [5] and others [6]. Research into PBL is an ongoing effort [7], and the level that it is used in the classroom does vary [8]. In Make to Innovate, PBL is a central and critical component to the learning environment, and we have designed the course to center around this learning technique. We do this by dividing all work into projects and placing the responsibility on the projects to complete their goals. Through a continuous assessment approach and advising the students throughout the semester, the students engage in learning new skills and applying current skills to a real world problem.

To implement this approach, we use a flipped classroom where the focus is on the students and distributes information informally. Both flipped classroom and PBL are student-centric and compliment each other. This concept has been used at other Universities and Rice University is one such example [9]. This flipped classroom approach can be advantageous as the students have the ability to take control of not only their learning, but how they approach the problem. However, like other flipped classrooms, some students may react in a negative fashion to the increased personal responsibility in the learning process [9].

While the use of a flipped classroom and project-based learning is not new, Make to Innovate takes these tools and applies them at a larger scale by having a variety of different projects over a wide range of engineering areas. While many do have a focus in Aerospace Engineering, others cover topics such as robotics and engineering manufacturing.

The project-based learning that we use is based on problem-based learning. Each project has one or more problems that need to be solved and often these problems can be broken down to smaller problems that each team can address. These problems are centered around the goal(s) of each project. For example, a competition project may need to build a rocket that exactly reaches 5,280 feet. This problem can be broken down to smaller problems such as the size of the motor, weight of the rocket, and other problems that contribute to the goal of obtaining that altitude.

The projects we have involve multiple disciplines and multiple problems to be solved. With the example of the rocket project, we have aerospace, mechanical, chemical, electrical and computer engineering disciplines that is involved. Students from different disciplines, backgrounds, and personal aspirations need to come together to solve the problems at hand. It is through this team-based and interdisciplinary learning that students gain insight and skills outside of those in a typical classroom. 

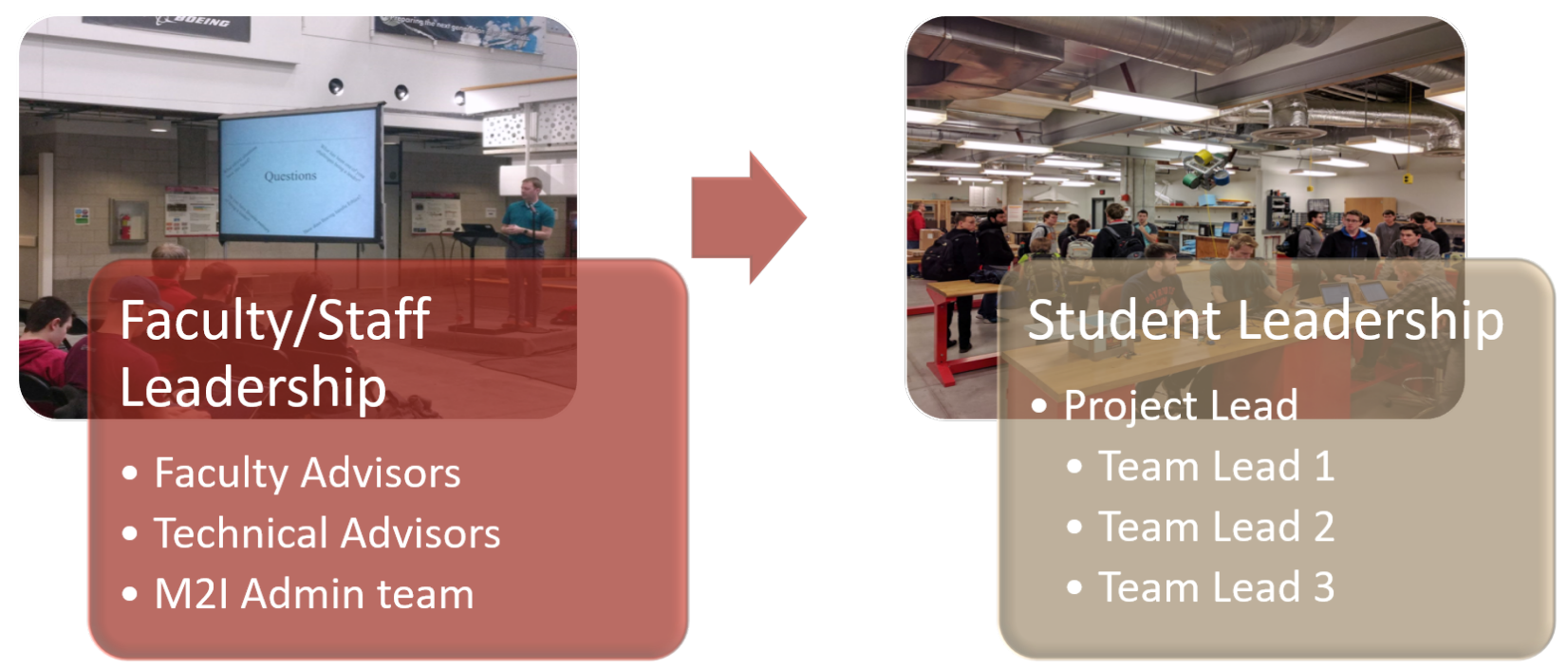

Figure 7: Key roles between faculty, staff and students in the M:2:I program.

\section{Implementation}

Make to Innovate is a program that is organized and run by the Aerospace Engineering department at Iowa State University. The program has a faculty member that serves as the director of the program and the instructor on record for the courses and oversees the curriculum, finances, and policies of the program. A staff member serves as a program coordinator and manages the day to day operation of the program and assists with the grading of materials.

Make to Innovate distributes the workload of managing approximately 200 students and 14 projects by using a combination of faculty advisors, technical advisors, and student leadership to help keep the projects on track and report any issues to the Make to Innovate administration team. Figure 7 shows how faculty and staff leadership works with student leadership to keep things on track.

All projects are required to have one faculty advisor. This advisor serves to guide the students academically and provides their expertise on the project. The faculty advisor also provides the most feedback in grading for their project that they are advising.

Technical advisors are advisors that are a combination of additional faculty members, graduate students, and engineers from industry from our industrial partners. These technical advisors provide additional technical information either from their research or from industry backgrounds. It is recommended that each project has at least two technical advisors, however, this is no set limit on technical advisors. Most projects within Make to Innovate has two to three technical advisors.

Implementation of our project-based learning approach is through a flipped classroom. In a flipped classroom the delivery of information or content is shifted from a formal lecture to informal sessions [10]. We deliver this information through the Iowa State University Learning Management System (LMS) called Canvas. All assignments and course information is delivered 
through this LMS.

Information is also distributed through meeting times that are set up throughout the semester. This allows us to conduct one on one time with the students and to cover topics such as professional development skills and project management skills. The first meeting that we conduct is the kick-off meeting at the beginning of the semester.

Students are required to meet with their faculty advisor and technical advisors on a bi-weekly schedule. Although the minimum requirement is bi-weekly, more frequent meetings are encouraged, and some projects will meet more often. These times are spent in guiding the students as they work through the project and to provide them feedback. Students are required to take meeting minutes and submit them. These minutes include who was present at the meeting, what was discussed, and what action items the students will be working on next.

To help facilitate communication and to encourage peer reviewing of the program we created an advisory board that consists of the faculty and staff running the Make to Innovate program, industry stakeholders, and students involved in the program. This advisory board then meets at least twice a semester and once over the summer to discuss Make to Innovate, what is working well and what needs improvements. The advisory committee has been instrumental in guiding the program and helped to keep in touch with the industry stakeholders that support to provide resources to the program.

We divided student projects into four types; competition, research, industrial and service. Each kind of project gives students experience in solving real-world problems. However, each one creates a different learning environment and slightly alters the experience for the students. We then divided each project into teams, usually between three and four teams for each project. Each project has a student project leader, and each team has a student team leader. This builds a chain of command and allows us to introduce other professional development skills such as teamwork and leadership. All projects are assigned faculty advisors that oversee the project and are there to guide the students in the problem-solving efforts. Some projects directly work our industry partners and in these cases the industry partner helps to establish the goals and purpose of the project. Students are also able to work side by side with engineers from these companies as they work towards their goals.

Competition projects are projects that are competing in a national or international competition that is managed by a known third party. Examples of these type of projects include a project that is competing in the NASA University Student Launch Initiative (USLI) competition, a project competing in the AIAA Design, Build, Fly (DBF) competition, and a project that is competing in the University Mars Rover competition run by the Mars Society.

Research projects are projects that are conducting research or new technology. These projects must work closely with their faculty advisor and the faculty advisor helps to guide the research the students are undertaking. These projects are working on cutting edge technology that will push the boundaries of technology.

Service projects are projects in which students are providing a service to others on campus. An excellent example of this project is our High Altitude Balloon Experiments in Technology (HABET) project. This project offers a service to be able to bring payloads up to altitudes of 
100,000 feet or higher and to help provide access to both students and faculty to these near-space conditions. Some past examples of this is working with faculty in plant pathology to measure the movement of rust spores or working with NASA to send worms to near space conditions. There have also been countless student projects such as performing short zero gravity experiments, photography opportunities, and measuring cosmic radiation.

Industry projects are projects that are directly tied to one of our industry partners. In industry projects, the sponsoring industry sets the requirements and acts as the client for the students. These projects will then work on real problems that the industry partner is working on. Students will work side by side with engineers from the industry partner to come up with solutions and test their solution in a lab environment.

Examples of some of the industry projects we have or are currently working on include working with Boeing and the feasibility of electric flight with commercial aircraft. Another project is working with Collins Aerospace and applying ADS-B technology to other aircraft such as Unmanned Aerial Systems (UASs). Both projects are examples of students working with industry experts and working on projects that are forward thinking and engaging students to think about problems that they may need to address once they have graduated from Iowa State University.

\section{Assessment}

Assessment of Project Based Learning (PBL) can often be challenging. As we also use a flipped classroom, the learning is shifted more to the students and requires a different set of assessment tools than the more typical homework, quizzes, and tests. To accommodate the fact each project is different and has different requirements, we set our assessment tools to be more flexible and perform more of a continuous assessment with checkpoints along the way. Figure 8 shows how the grading is divided and what we consider to be a project, team, and individual student effort.

We divide the grading of the course into the following areas:

- Advising Committee Grade - 30\%

- Mid-term Design Review - 10\%

- Final Presentation - 10\%

- Advising Committee Evaluation - 10\%

- Weekly Reports - 35\%

- Website Updates - 15\%

- Attendance - $10 \%$

- Cross Evaluation - 10\%

Advising Committee Grade. The advising committee's grade is a grade comes from the faculty advisors and technical advisors for each project and is $30 \%$ of the students' grade. This grade is 


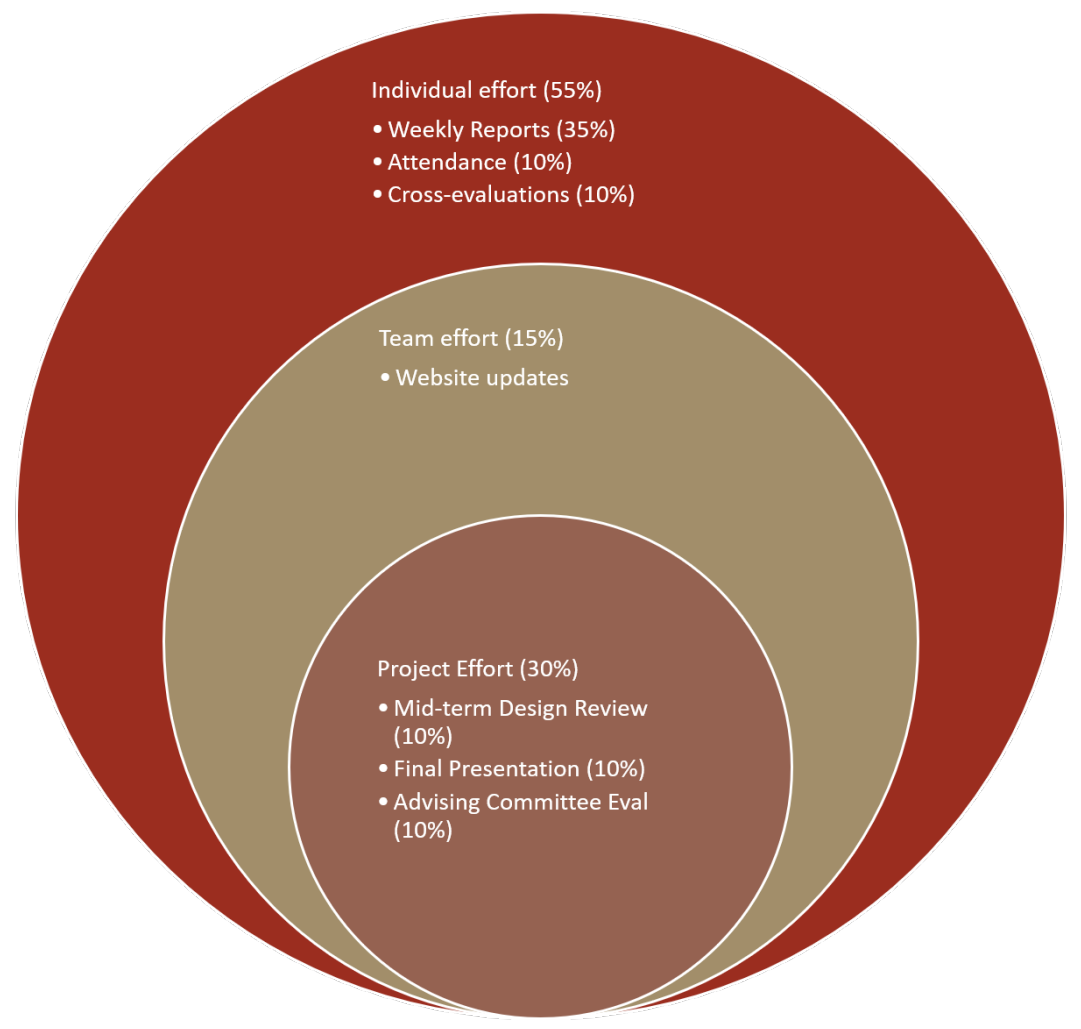

Figure 8: Visualization of how grading is accomplished at the project, team and individual level.

made up of three parts, a mid-term design review, a final presentation, and a direct evaluation from each member. The mid-term design review counts for $10 \%$, the final presentation is $10 \%$, and the final review is also $10 \%$ for a total of $30 \%$.

The mid-term design review is an informal presentation made by the students to all stakeholders and counts as $10 \%$ of their grade. This design review is an hour-long presentation with a question and answer time at the end. The presentations are streamed so that advisors that are off campus are also able to participate in the discussion. These design reviews are designed to give all stakeholders an update on where the students are at such as what has been completed and any issues that have come up. Feedback is also provided to the students as to what they can improve and suggestions to move the project forward. By holding this half-way through the semester, we hope to give students feedback and recommend any changes that might need to be made before it is too late.

The final presentation is a formal presentation given by the students in each project at the end of the semester and counts as $10 \%$ of their grade. This presentation presents or demonstrates what work was performed over the semester and what was successful and was not successful. Students are evaluated on the progress they made, and how well they achieved their goals, they said they would at the beginning of the semester.

The remaining $10 \%$ is an overall assessment they have of the project as a whole. Faculty and technical advisors may elect to grade the entire project with one grade or to assign a grade to each student individually. A survey is sent out to collect this information from each advisor. This 
survey also asks for information such as how well they communicated with them and their overall progress.

Weekly Reports. Weekly reports are an essential part of the assessment of the student, and as such it carries significant weight with it counting for 35\% of the students' grade. Every student does a weekly report, and each weekly report is an individual effort. Students that are in a leadership role provide additional information such as the status of their team or project.

Weekly reports are graded on several criteria. We first look to see if the students are providing the correct information. This includes details such as their name, project, team and the tasks they are reporting. We do make sure that students are submitting reports with proper grammar and no spelling errors. We then examine what the students are working on by looking at the tasks the students are working on and how that relate to the goals of their team. We also look to see that progress is being made. If a task remains on the report for more than four weeks, for example, then perhaps there is an issue. If a problem does come up, we can then speak to their team lead or if needed their project leader to intervene. In general, weekly reports can be a reasonably painless process, if students are working on items and remember to submit them.

While the weekly reports are an assessment tool, they also provide information on how things are proceeding with the project. Through the weekly reports, we can see how the overall progress is going, and most students will also report issues or problems that they are facing. This allows us to intervene or investigate an issue if we need to. Make to Innovate has approximately 200 students in fourteen different projects it is critical that we have a method to check in all students to make sure no one is left out.

Website updates. Each project in Make to Innovate has a website that they can use to show and display the work they have done. These sites are WordPress sites and are designed to be reasonably easy to use and update. Each team must update their team site on the project website. There are three checkpoints where students are requested to update the website with whatever updates they have. We then examine the updates and grade the students accordingly.

Grading of the websites includes that they have no spelling errors and are grammatically correct. As these are public websites, we also look for a professional looking website and that the information is accurate. These website updates give us additional information on how the team is progressing and allows the teams to use multi-media such as pictures and videos also to explain what progress has been made. This is a team effort grade and counts as $15 \%$ of the students' score.

Attendance. Attendance is a score of how often students are attending their weekly meetings and other events determined to be required by the instructor. This score is an individual effort and counts as $10 \%$ of the students score. Grading for this score is done through an electronic method that requires the students to scan their student ID card.

All students are required to attend at least one weekly meeting. This weekly meeting is with their team that they have been assigned too. Other events are also identified that students are required to attend. These are informational sessions held periodically throughout the semester. These often involve guest speakers or meetings that may discuss an area in professional development skills or project management. 

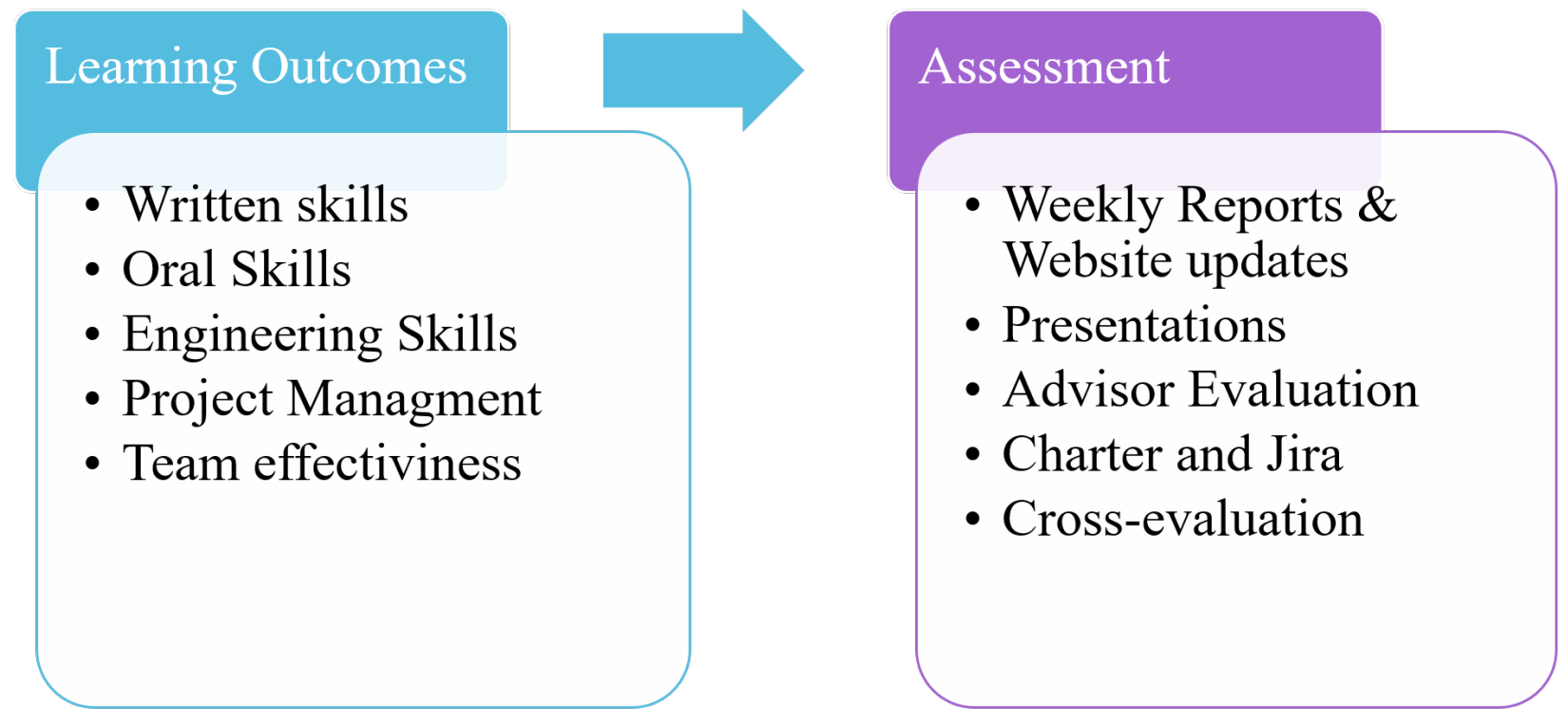

Figure 9: Generalized visualization of our learning outcomes and associated assessment.

Attendance to the design reviews and final presentations are also required. Students are required to attend at least two other final presentations and at least one other mid-term design review. This encourages students to peer evaluate the other projects within Make to Innovate and provide other groups feedback.

While the minimum requirement is that students meet at least once a week, most teams meet more often. Most teams will have a group meeting at one time and then a "work day" at another time. It is usually at these workday meetings that students will collectively work on their tasks.

Cross evaluations. Cross evaluations are given to students twice a semester, one at mid-term and the other at the end of the semester. These evaluations have the students evaluate how well they are working as a team. A reason we conduct these at mid-term is to identify any potential problems with a team early instead of at the end of the semester when there is usually nothing more that can be done. Evaluations were conducted with a survey, however starting in the Fall 2018 semester we switched to the Comprehensive Assessment of Team Member Effectiveness or CATME tool [11].

Cross evaluations also help us to receive feedback from the students as well. We will examine some of this feedback in the Results section below. However, this feedback is used to help determine what assessment is and is not working. It also provides us with information regarding any issues with the teams and if so, we can examine what needs to be done to find a solution to the situation.

Our learning outcomes are assessed by using the assessments discussed in this section. Figure 9 shows a generalized view of our outcomes and associated assessment. Some assessments are used to evaluate several outcomes. For example, our design reviews and final presentations are used to evaluate oral, written and the students engineering skills and how they are applying those skills. 
The advisor evaluation is also used to not only evaluate the engineering skills of the students but also how they interact and how they present their work to the advisor. However, we the image shown in Figure 9 as a guideline to ensure we have covered our learning outcomes.

\section{Results}

To look at the results, we need to recap what our goals for this program are. Our goal with this program is to engage students in hands-on learning and to expand their knowledge to beyond the classroom. Students should apply their existing knowledge and learn new skills on taking a project from idea to completion. We also want our students to learn professional development skills, which are often not taught in most engineering courses [12]. If students have learned additional skills in taking a design to completion and learned some new skills in professional development, then we have met our goal of teaching our students additional skills.

The success of the Make to Innovate program is in our students. One way that we measure success with the project is if the students honestly felt that they learned something through the process. Even if a project did not meet all of their objectives or goals, if the students learned something in the process and are able to explain what those were, we take that as a success.

Figure 10 shows quotes from students with comments that were made in their cross evaluation survey. In the polls that we distribute, students are asked if they have additional comments for the instructor. Many students will use this to outline both the good and bad of the program, and we use these to improve the program. Figure 10 shows some of the positive feedback we have received from students.

This is not to say that Make to Innovate does not have problems or students that are unhappy. Students have complained that the additional paperwork required for the class distracts from them working on the project. Others have complained because of a process involved with the Make to Innovate program such as ordering parts. However, the majority of students involved have reported that they enjoy the program. Our high enrollment rate which can be seen in Figure 2 is evidence that students enjoy the program and that they feel it is a benefit to them.

Another source of information for how successful the program is, is with our advising committee. Our advising committee consists of members in industry that are often hiring our students for co-ops, internships, and full time employment. Because of that, their feedback is invaluable and we use their feedback to improve the program. We have received consistently positive feedback from our advising committee that what we do in exposing students to real world problems has a positive effect on them and is often a reason why they hire our students.

\section{Lessons Learned}

Throughout the seven-plus years that we have run this program, we have learned some valuable

lessons over the years. We have learned through this process that we need to examine and update our assessment process continually. We wish to ensure that our students are successful and have 


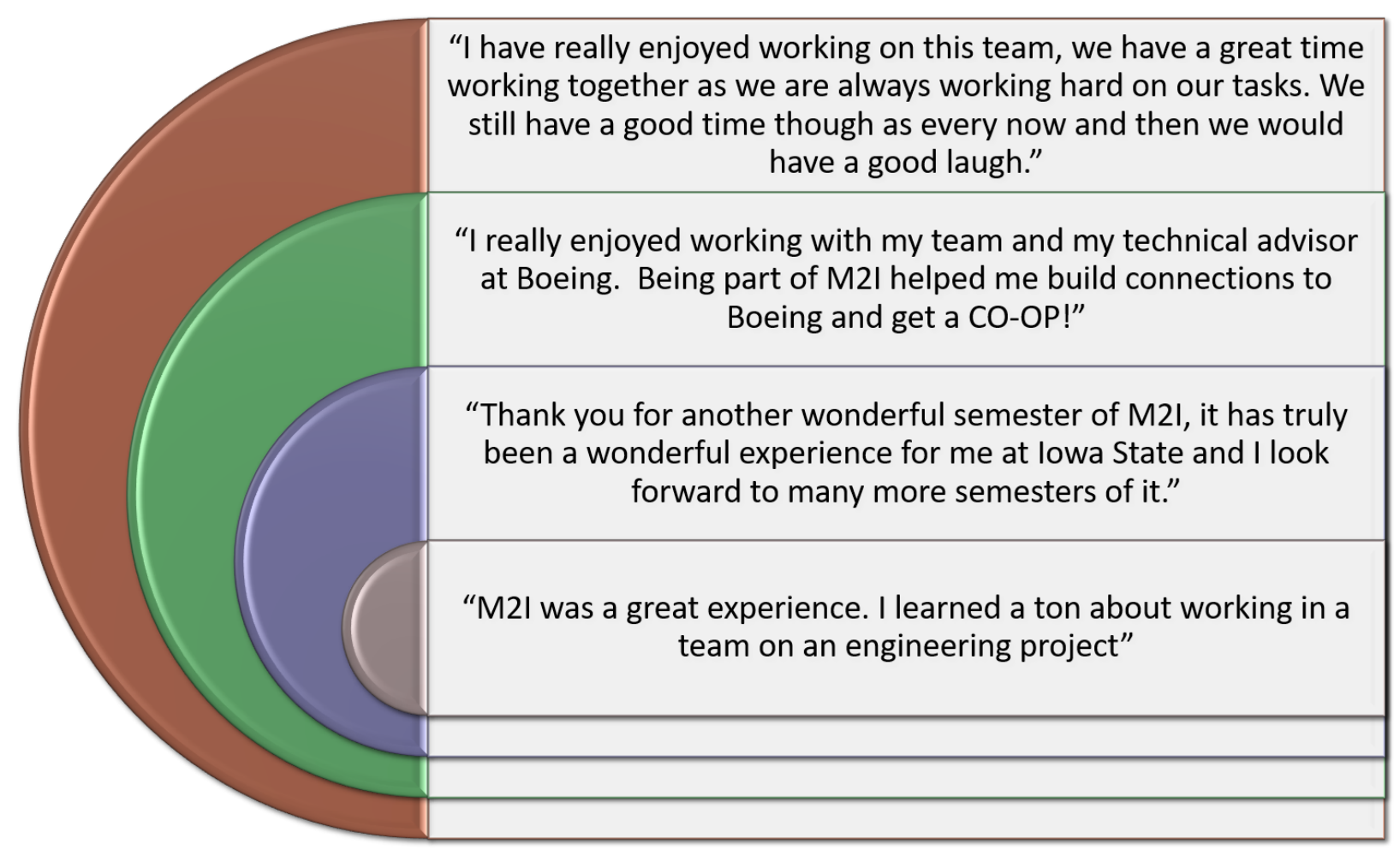

Figure 10: A sample of quotes from students in the Make to Innovate program. 
learned some skills along the way. However, if you add too many assessments in a project-based learning environment, you can distract from the project-based learning.

We designed this program as a flipped classroom and it is expected that students are working on their tasks throughout the semester. However, without class-time or extra face-time with the students, it is easy for some students to get lost in the learning process. It is for this reason that continuous assessment is important and we have learned that while too much assessment may discourage students, not enough may result in students not learning as they are actively participating in the process.

One lesson we have learned from our experience is to perform smaller but continuous assessments throughout the semester and to take advantage of newer technology. We have recently changed to using Jira as a method to track progress and continuously assess the students project. Jira is a project management tool and it is able to track milestones, tasks, and sub-tasks assigned to students. It is a professional tool that allows the Make to Innovate team to simultaneously track multiple projects and examine progress on tasks through reports. Students are able to generate a report that we then grade as part of their weekly report. Because we are able to track multiple projects, we can also generate reports on the project itself to see how well the project is operating and even do comparisons with other projects within the program.

Another lesson we have learned is not to treat assessments as a one-way street. You can use assessments as an opportunity to not only assess your students but to also provide them with valuable feedback. The design reviews we conduct are designed for just this purpose. We use this to determine where the students are, but we also use this as an opportunity to give feedback and in some cases directly to the students as they work on their project. This two-way communication between the instructors and the students not only help the instructors in evaluating the students but also help the students in learning not only technical information but even on the importance of communication and improving their communication skills.

This two-way communication also includes getting valuable feedback from the students. We have kept an open door policy that students may come and discuss if they are either having issues with some of the requirements from the program or feel that something should be changed. This policy has helped to steer the program into one that has kept both students, faculty and staff engaged and part of the learning process.

Faculty, staff, and advisors from outside the university are critical to the success of the program. With project-based learning, it is imperative that you have an advisor or mentor that is working alongside the students. We learned that by incorporating both faculty and industry experts, we could provide the right kind of guidance that students often need. The faculty is vital in ensuring the expertise and the theoretical background for the various topics and disciplines the projects entail. Technical advisors from industry, however, provide their knowledge in carrying ideas from the notebook to the real world. Staff members are also invaluable in providing the support needed to not only help run the program but the facilities. 


\section{Future Work}

Another area for future work is in the assessment of the students. We have an obligation as a University to provide our students education and one method for ensuring that takes place to assess the students work. However, we also do not wish to burden the students with so much assessment work that they are not able to complete their projects. One method that may help to allow for continuous assessment yet keep the overhead on the students low is the use of new technology. Recently, we implemented a Jira server. Jira is a project management suite of software that allows for the tracking of tasks and milestones. This will enable us, but further research and testing need to be conducted on how this tool will fully integrate with Make to Innovate our learning objectives.

We are looking into providing resources to students to overall help them to be better engineers to also improve the success of their projects in Make to Innovate. This involves teaching students such skills such as project management and using tools like Jira. It also includes teaching them other professional development skills such as leadership, communications, and teamwork. Doing so will aid our students in becoming better engineers. Because Make to Innovate is open to students from the freshman level to the senior level, we hope to reinforce these skills throughout their academic career continuously.

\section{Conclusion}

We believe that the Make to Innovate program is helping our students in learning additional skills such as professional skills, manufacturing skills, and moving a design to reality. These skills will help our students in becoming better engineers and give them experience that can help them in their future careers. The data we have collected so far have shown that we are making an impact on students and that employers have taken notice of the benefit of the program. As with any program though, continuous assessment and improvement are needed to keep the program successful in accomplishing its goals. We will continue to improve this program and strive to serve our students to the best of our abilities. 


\section{References}

[1] M. F. Cox, C. Osman, B. Ahn, and J. Zhu, "Engineeirng professionals' expectations of undergraduate engineering students," Leadership and Management in Engineering, vol. 12, no. 2, pp. 60-70, 2012.

[2] L. J. Shuman, M. Besterfield-Sacre, and J. Mcgourty, "The ABET "Professional Skills" - Can they be taught? Can they be assessed?" Journal of Engineering Education, vol. 94, no. 1, pp. 41-55, 2005.

[3] M. E. Nelson and B. Ahn, "Improving engineering students professional development skills in the ,Make to Innovate program," in 2017 IEEE Frontiers in Education Conference (FIE), Indianapolis, IN, 2017, pp. 1-5.

[4] C. R. Rupakheti, M. Hays, S. Mohan, S. Chenoweth, and A. Stouder, "On a pursuit for perfecting an undergraduate requirements engineering course," Journal of Systems and Software, vol. 144, pp. 366-381, 2018.

[5] A. Wiek, A. Xiong, K. Brundiers, and S. van der Leeuw, "Integrating problem and project-based learning into sustainability programs: A case study on the school of sustainability at Arizona state university," International Journal of Sustainability in Higher Education, vol. 15, no. 4, pp. 431-449, 2014.

[6] A. Yadav, D. Subedi, M. A. Lundeberg, and C. F. Bunting, "Problem-based learning: Influence on students' learning in an electrical engineering course," Journal of Engineering Education, vol. 100, no. 2, pp. 253-280, 2011.

[7] J. Strobel and A. van Barneveld, "When is PBL more effective? A meta-synthesis of meta-analyses comparing PBL to conventional classrooms," Interdisciplinary Journal of Problem-based Learning, vol. 3, no. 1, pp. 44-58, 2009.

[8] A. C. B. Reis, S. C. M. Barbalho, and A. C. D. Zanette, "A bibliometric and classification study of Project-based Learning in Engineering Education," Production, 2017.

[9] A. Saterbak Tracy Volz and M. Wettergreen, "Implementing and assessing a flipped classroom model for first-year engineering design," Advances in Engineering Education, vol. 5, no. 3, 2016.

[10] A. Butt, "Student views on the use of a flipped classroom approach: Evidence from Australia." Business Education \& Accreditation, vol. 6, no. 1, p. 33, 2014.

[11] M. W. Ohland, M. L. Loughry, D. J. Woehr, L. G. Bullard, R. M. Felder, C. J. Finelli, R. A. Layton, H. R. Pomeranz, and D. G. Schmucker, "The comprehensive assessment of team member effectiveness: Development of a behaviorally anchored rating scale for self- and peer evaluation," Academy of Management Learning and Education, vol. 11, no. 4, pp. 609-630, 2012.

[12] M. E. Nelson and B. Ahn, "Virtual reality activities for teaching engineering students professional development skills," in FIE, San Jose, 2018. 